\section{Zahlen des Monats}

\section{Teures System}

Hermann Gröhe sei vielleicht der teuerste Gesundheitsminister, den das Land jemals hatte. Das behauptete der Gesundheitsökonom des Rheinisch-Westfälischen Wirtschaftsinstituts (RWI) Boris Augurzky gegenüber der „Welt am Sonntag“. Laut RWI-Berechnungen, die der Zeitung vorliegen, kosten die zahlreichen Reformen des Ministers zwischen 2015 und 2020 bis zu 40 Milliarden Euro extra. Für die Beitragszahler bedeute das: Sie müssen allein im Jahr 2020 7,2 Milliarden mehr zahlen als heute.

\section{Teure Station}

Bereits deutlich gestiegen sind die Kosten für stationäre Krankenhausbehandlungen. Nach Angaben des Statistischen Bundesamtes verschlang der Klinikaufenthalt eines Patienten 2014 im Durchschnitt 4239 Euro. 2013 waren es noch 4,1 Prozent weniger. Am billigsten war im vergangenen Jahr der Klinikaufenthalt in Sachsen-Anhalt mit 3808 Euro und am teuersten mit 4893 Euro in Hamburg. Dabei spielten die Personalkosten, die den Hauptanteil der Belastungen ausmachen, sicherlich eine große Rolle. Insgesamt sind die stationären Krankenhauskosten von 78 auf 81,2 Milliarden Euro gestiegen.

\section{Arme Senioren}

Nicht nur das Gesundheitswesen frisst Geld. Auch das Leben an sich birgt viele finanzielle Fallstricke. Das führt dazu, dass in Deutschland trotz anhaltender guter Konjunktur sehr viele Verbraucher überschuldet sind. Wie der aktuelle Schuldneratlas von Creditreform ausweist, sind rund 6,7 Millionen Bürger über 18 Jahre nicht mehr in der Lage, ihren Zahlungsverpflichtungen nachzukommen. Das sind 44.000 mehr als im Vorjahr. Besonders betroffen sind ältere Menschen. Zwischen 2013 und 2015 stieg die Zahl der überschuldeten Senioren um mehr als 35 Prozent auf 150.000. Im bundesweiten Vergleich gibt es von Bundesland zu Bundesland große Unterschiede. Während in Bayern nur 7,12 Prozent der Schuldner leben, zählt Berlin mit 12,99 Prozent die meisten.

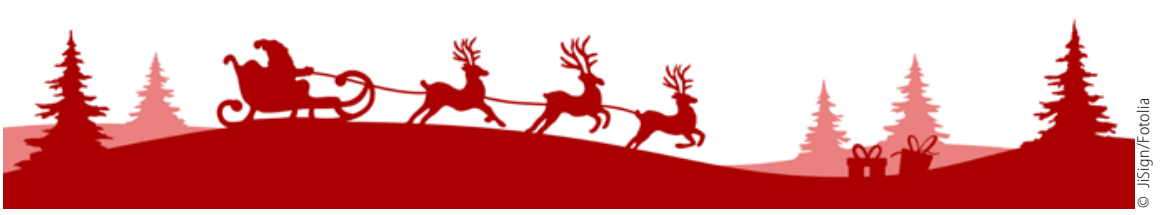

\title{
Frohe Weihnachten und ein gutes neues Jahr!
}

Wie die Zahlen des Monats glasklar belegen, hat Gesundheitsminister Hermann Gröhe seit seinem Amtsantritt einiges angestoßen. Und so waren in diesem Jahr auch wieder zahlreiche Gesetzesvorhaben und bereits verabschiedete Gesetze für das Gesundheitswesen im Dauergespräch. Leider nicht immer positiv. Aus Sicht der Zahnärzte stehen einige Pläne der Großen Koalition unter keinem sonderlich guten (Weihnachts-)Stern. Daran wird sich auch 2016 nichts ändern.

Die im E-Health-Gesetz verankerten Sanktionsmechanismen oder der pauschale Generalverdacht gegen die Heilberufe, den das geplante Antikorruptionsgesetz impliziert, sind nur zwei Beispiele dafür, was auf die Zahnärzteschaft in naher Zukunft zukommen dürfte.

Auch längst noch nicht beendet ist das Thema Flüchtlinge. Inzwischen sind sehr viele Zahnärzte mit Menschen in Berührung gekommen, die aus ihrer Heimat nach Deutschland fliehen, um Angriffen des IS und Bürgerkriegen zu entkommen. Einige von ihnen landen mit akuten Zahnschmerzen in deutschen Zahnarztpraxen. Und mit dieser Situation gilt es umzugehen - in vielerlei Hinsicht.

Zum Jahresende extrem zugespitzt hat sich die Terrorgefahr in Europa. Angst und Schrecken sind auch in Deutschland angekommen. Angesichts dieser neuen Dimension der Gewalt muten die Tücken des Gesundheitswesens nahezu banal an. Aber der Alltag, das gewohnte Leben, muss und soll weitergehen. In diesem Sinn ist das Weihnachtsfest 2015 eine gute Gelegenheit, einmal Pause zu machen von den Erlebnissen der vergangenen zwölf Monate. Die DFZ-Redaktion wünscht ihren Lesern ein frohes Weihnachsfest, erholsame und friedliche Feiertage sowie einen guten Rutsch ins neue Jahr.

Melanie Fügner, Sabine Schmitt, Dr. Joachim Hüttmann (DFZ-Chefredakteur)

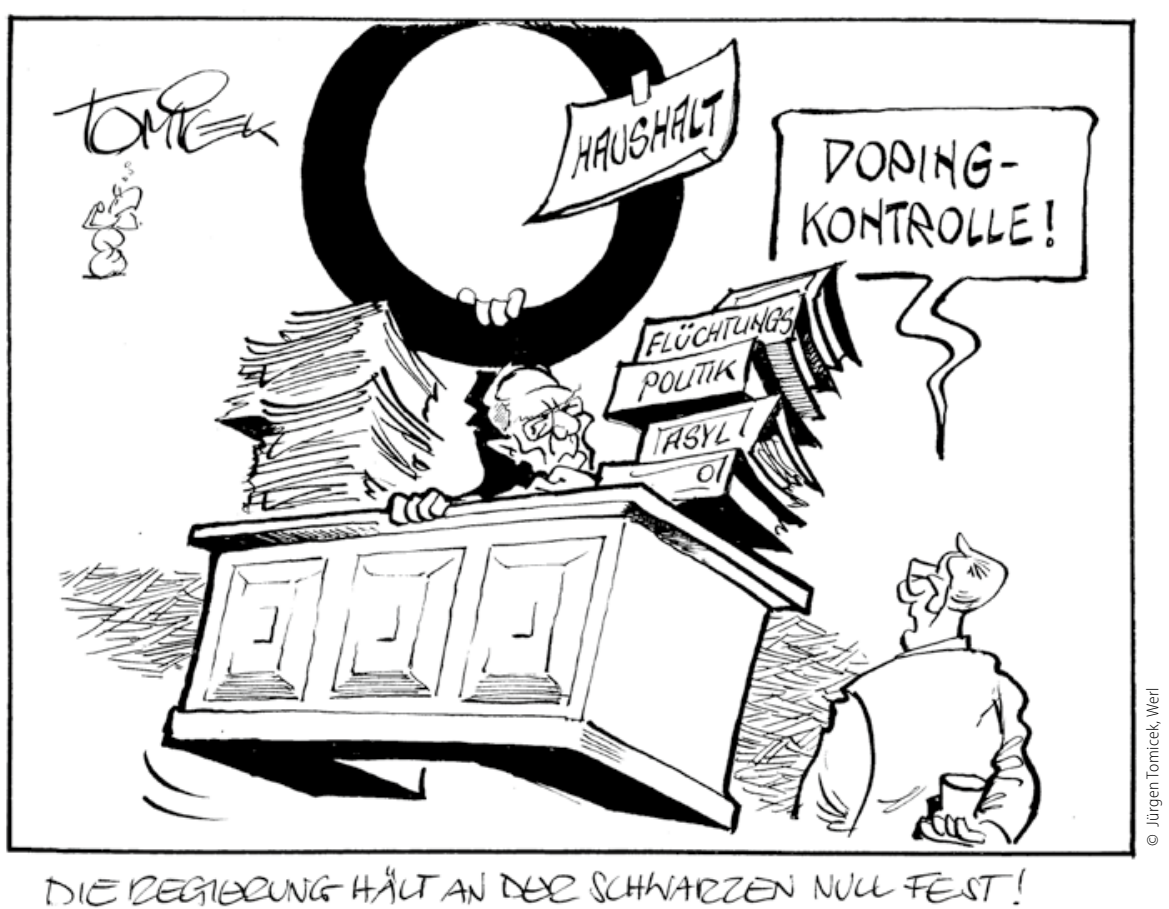

